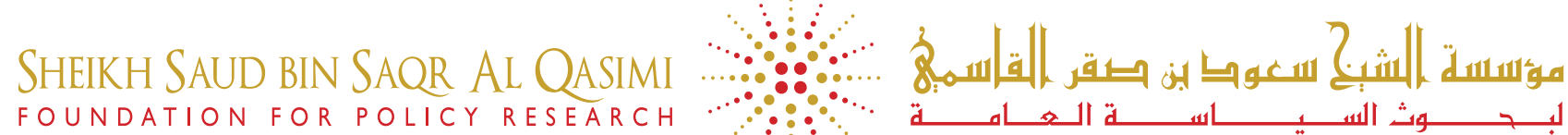

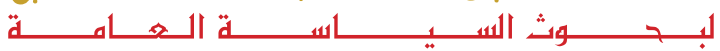

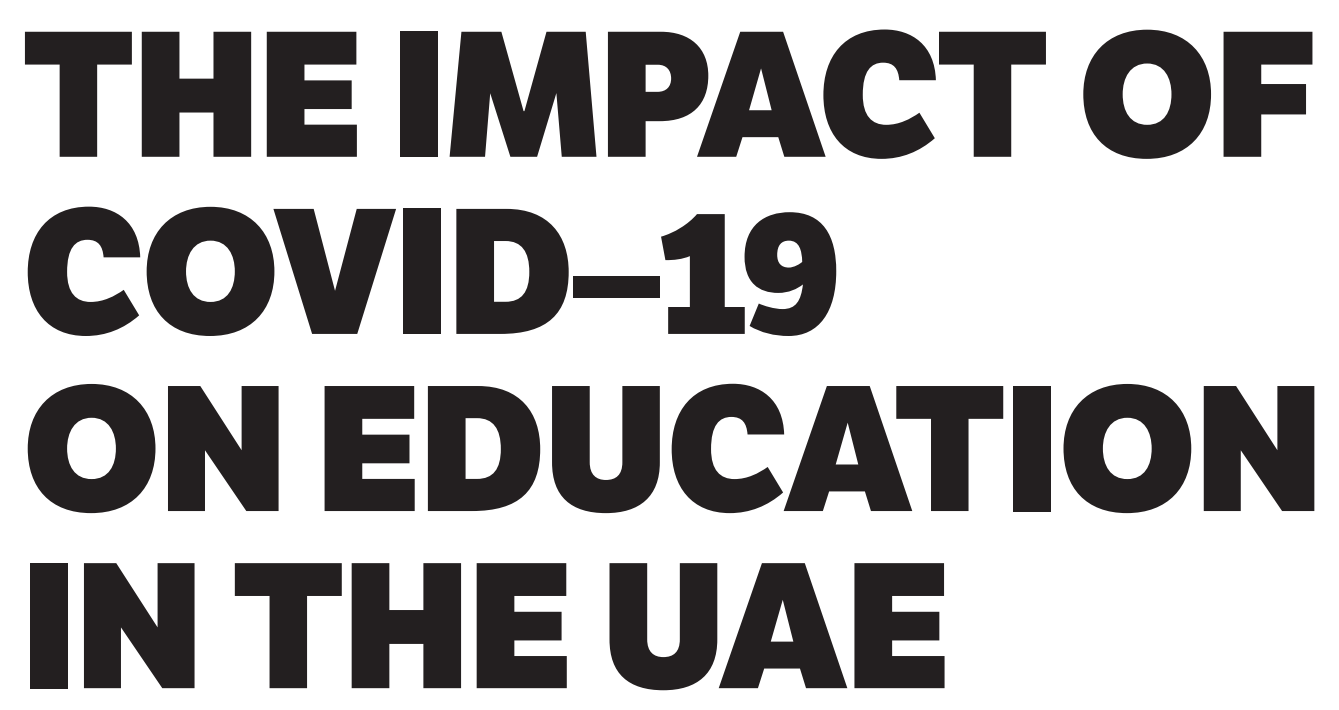




\section{The Impact of COVID-19 on Education in the UAE}

The closure of schools in 191 countries around the world in the same window of time in response to the COVID-19 pandemic is unprecedented. It has left school systems and governments scrambling to find approaches and solutions to ensure that education continues uninterrupted and that the most vulnerable children are not left further behind. This report seeks to provide guidance based on data collected and analyzed by the Al Qasimi Foundation in April 2020. After surveying approximately 700 participants and interviewing several experts, findings in four areas emerge. First, training for staff, students, and parents is low, although all feel well prepared. Second, the work of administrators and teachers has become particularly stressful, as well as distance learning for students and parents. Third, working parents face additional challenges. Fourth, children with learning disabilities or special needs lack sufficient support.

Going forward, schools need to be better prepared to support students and staff for future outbreaks to mitigate the risks to learning. One solution might be to make the structure and content of school days more flexible, ideally with on-demand content for learners and project-based approaches to teaching and learning. Schools must prioritize supporting the most vulnerable groups, and parents need to be actively involved in their children's distance learning. This, however, is a challenge for working parents. In its current form, distance learning threatens to foster economic and social inequality if risks to accessing quality education are not addressed. Efforts need to provide support for parents of children from low income groups and those in remote areas to build structures for distance learning that can reach all children, including TV and radio channels.

\section{Overview of the UAE's Responses to COVID-19 in the Education Sector}

- Public and private schools temporarily closed their facilities to staff and students beginning March 2020

- The Ministry of Education (MoE) provides information via its homepage and u.ae

- Distance learning approaches were rapidly expanded and implemented

- The MoE provides guidelines for managing students' behavior online, information about free satellite broadband services for remote areas, free mobile internet packages, and existing eLearning, mLearning, and distance learning programs and tutorials

- Public school students recently took centralized remote tests

- Distance learning school evaluations have been implemented by the MoE

- Current scenarios anticipate the continuation of either fully remote distance learning or a blended model that combines onsite and online learning for the first semester of the next school year going into 2021

\section{Public Sector}

- A plan for distance learning has been implemented in public schools and a 'Smart Learning Platform' is being used by teachers and students, but information about the platform is scarce

\section{Private Sector}

- The MoE has sent advisory plans to private schools following its curricula and to private schools following other curricula, with the freedom to choose whether the same plan is implemented, or another is developed

- Private schools either expanded existing eLearning tools or started using platforms, such as Google Classroom, Microsoft Teams, Zoom, or apps such as ClassDojo

- Private schools are under financial pressure due to the reduction or even absence of fees 


\section{Background \& Context: Challenges to Learning During the Pandemic}

As a response to COVID-19 health and safety risks, 191 national governments closed their schools by mid-April 2020 (McKinsey \& Company, April 2020). The challenges that this response creates for school systems, students, parents, teachers, and administrators are unprecedented. Early research indicates that students are unequally impacted by the current situation depending on social factors. For instance, before the pandemic, online platforms were already implemented at $60 \%$ of private and $37 \%$ of state schools in affluent UK areas, but only at $23 \%$ of schools in underprivileged areas (Sutton Trust, April 2020). While online platforms are an important first step, the learning environments at home are also crucial for students' ability to learn. Students need a quiet place to study and resources such as a computer and internet access. Unfortunately, we know that these resources are less likely to be available in low-income families. Also, social isolation, concerns about the virus, and worries about the family's financial situation create dangers to physical and mental health that remain unclear.

This report seeks to provide more information about the COVID-19 induced challenges that local students, parents, teachers, and administrators face to inform evidence-based policy making in education in the United Arab Emirates (UAE). Against this background, the report discusses and presents findings from a survey distributed in the UAE. First, it explains the data and evidence base as well as its limitations. Second, it presents the key findings of our survey data along with supplementary interview findings around four main topics. Last, it offers four recommendations for the UAE to address the challenges to education during and post COVID-19 in the medium- to long-term and also highlights potential quick wins and best practices from other countries.

\section{Data \& Evidence}

The Foundation distributed an online survey in mid-April 2020 through our networks in the UAE, targeting students, parents, teachers, and administrators in public and private schools. Over a period of two weeks, approximately 700 participants took the survey. $77 \%$ of our participants are female and half of all participants are Emirati. The other participants include non-Emirati Arab nationalities, South Asians, Europeans, North Americans, Africans, and others (distribution from greatest to least, in that order). The distribution of students and parents is relatively equal with about $25 \%$ each, while the other $50 \%$ is made up of approximately $40 \%$ teachers and $10 \%$ administrators. The survey has 49 closed- and open-ended questions that allow for an analysis of responses relative to school curriculum. We conducted additional interviews via phone with selected education experts.

\section{Charity Schools and Distance Learning in Ras Al Khaimah and the UAE}

Ras Al Khaimah (RAK) has a network of four charity schools with approximately 2,000 students enrolled, under the purview of the Sheikh Saud bin Saqr Charitable Educational Foundation. These boys' and girls' schools offer the official Ministry of Education (MoE) curriculum taught by MoE teachers free of charge to expatriates who cannot otherwise afford an education. The schools are funded by the government of RAK and public donations. Similar charitable educational institutions known as the National Charity Schools in Dubai, Sharjah, and Ajman were founded by the Dubai Educational Zone Parents Council, headed by HE Juma AlMajid and have over 9,000 students enrolled (Juma Al-Majid Center, 2020).

Disasters such as the COVD-19 pandemic affect the vulnerable and disadvantaged most by further limiting their access to education. In interviews with administrators from the Sheikh Saud bin Saqr Charitable Educational Foundation, they cited a lack of technology to access distance learning as a key challenge as children from these schools tend to come from homes without laptops or reliable internet connections. Those from homes with laptops and tablets often have to share devices with siblings who are also attending online classes.

To address these needs, the charity schools launched a laptop drive, distributing 850 laptops to families in RAK who lacked resources. The Sheikh Saud bin Saqr AI Qasimi Foundation for Policy Research partnered with the charity foundation and other organizations in supplying these laptops. Charity schools in RAK also applied to the MoE for internet packages to provide access to families who were financially constrained. Across the UAE, other charities including the Pakistan Association Dubai, Sandooq al Watan, and the First Abu Dhabi Bank partnered with the MoE to also provide laptops to families in need across the country (Nasir, 2020b). Nonetheless, challenges continue for charity schools including difficulty enforcing student attendance and engagement, weak or inconsistent internet connections, and a lack of parental involvement. 


\section{Limitations}

The survey sample is not completely representative of the UAE due to barriers in access and information about the survey. This is in part driven by the survey being distributed online, which likely resulted in reaching those administrators, teachers, parents, and students who are the most digitally connected, literate, part of our networks, and have available time. As a result, the responses of the most vulnerable populations are likely to be missing due to shortages of time and resources, including limited access to electronic devices or an internet connection. One example of those vulnerable groups are the students who are attending charity schools in the UAE, which enroll about 14,000 students across the country. As a result, this sample is biased by the types of respondents who participated and is not representative of the UAE's population. Nonetheless, these results provide valuable insight into the current distance learning landscape in the UAE by identifying some of the key challenges faced by schools, students, and parents during this challenging time.

\section{Findings}

This section presents four main findings. First, it discusses the paradoxical situation where many administrators, teachers, parents, and students received little training to preprare them for distance learning, yet feel relatively well prepared. Second, it discusses how the work and school day has become more stressful for educators and learners in response to COVID-19. Third, it presents findings on the complicated situation for working parents, especially for those from low socioeconomic backgrounds, who face compounded stress from having to work while also caring for their children and supporting their learning at home. Lastly, this section discusses concerns about the limited support for children with learning disabilities.

\section{Despite Little to No Training for Online Education, Most Stakeholders Feel Well Prepared}

\section{Key Takeaway:}

- All four groups-administrators, teachers, parents, and students- have received little to no formal training for distance teaching or learning.

Results from the survey show that the majority of participants received less than a day of formal distance learning training. In addition, a significant share, between $14 \%$ to $47 \%$ of respondents in some categories, reported having received no training at all (see figures 1 and 2). However, the majority of respondents reported feeling well prepared to engage in distance learning.
Figure 1: Formal Training and Preparedness at Public Schools

\section{Training \& Preparedness}

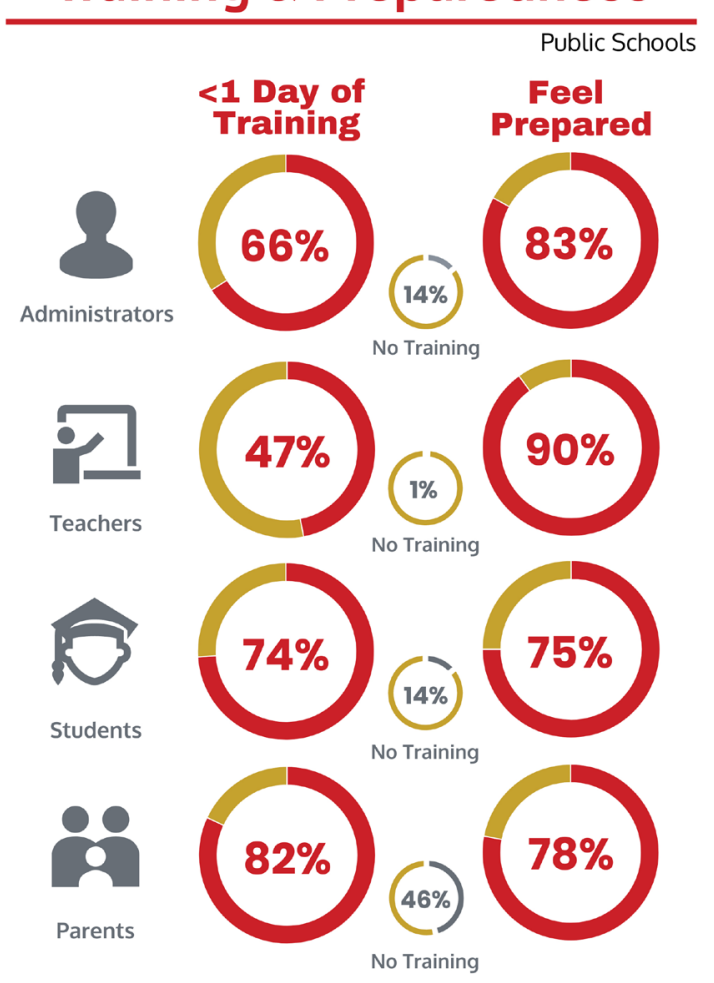

Teachers at both public and private schools received the most training in comparison to administrators, parents, and students. There was also more training provided for teachers at public schools than at private schools (see figures 1 and 2 ). While nearly all school teachers at public schools received some form of training, only $23 \%$ of teachers at private schools received more than 1 day of training, and $15 \%$ of private school teachers reported having received no training at all.

A similar pattern emerged for students: $74 \%$ of public school students received less than 1 day of training, in comparison to $88 \%$ of private school students. In addition, $14 \%$ of students at public schools reported that they received no training at all. This situation is even worse for private schools where $42 \%$ of all surveyed students reported not having participated in any formal distance learning training (see figures 1 and 2).

Both public and private school administrators received more training than students, but less training than teachers. The amount of training is still low overall, with $66 \%$ of administrators at public schools, and $85 \%$ at private schools having received less than 1 day. Similar to other groups, $14 \%$ of public school administrators, and $24 \%$ at private schools, reported having no formal training at all (see figures 1 and 2).

The support for parents at both public and private schools is reported to be quite similar. $82 \%$ of parents of students in public schools reported less than 1 day 
Figure 2: Formal Training and Preparedness at Private Schools

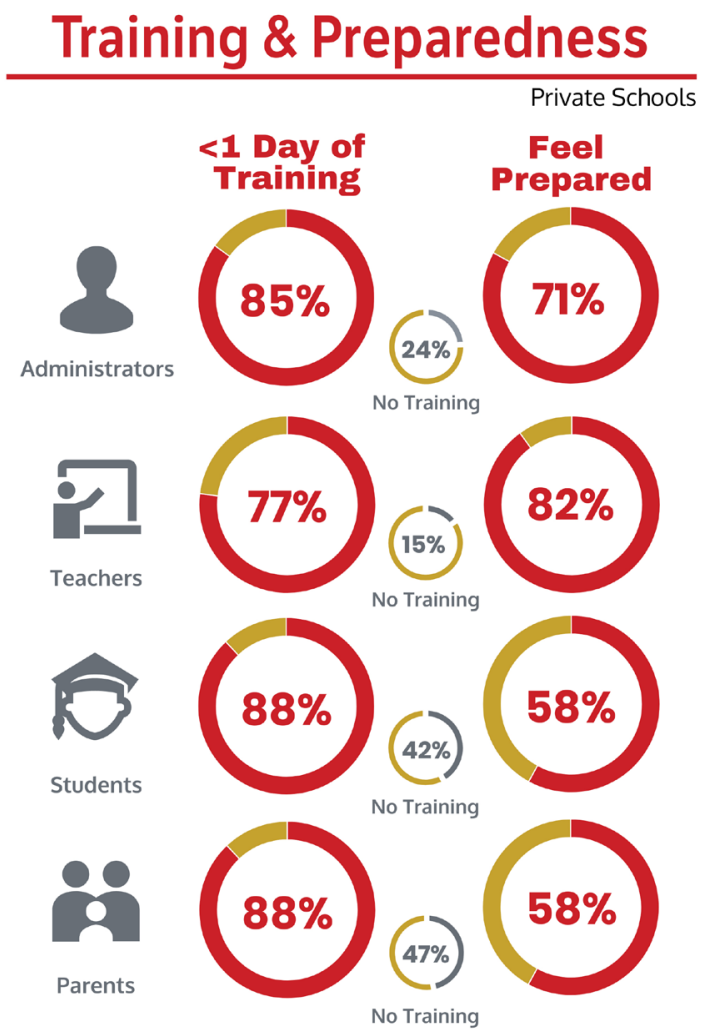

of formal training, while this number is slightly higher for private schools at $88 \%$. In addition, approximately half of all surveyed parents reported that they had not received any training for distance learning (see figures 1 and 2).

Despitereceiving littletraining, the majority of participants across the four groups indicated that they felt prepared to engage in distance learning. Respondents at public schools were more likely to consider themselves prepared for distance learning than their peers at private schools. Across all groups, teachers reported the highest levels of preparedness with $90 \%$ at public and $82 \%$ at private schools, followed by administrators. Students and parents overall reported similarly lower levels of preparedness with approximately $75 \%$ and $58 \%$ at public and private schools, respectively (see figures 1 and 2). Overall, our results indicate that public schools provided more formal distance learning training for their stakeholders, on average, than private schools. In addition, respondents at public schools feel better prepared for distance learning overall. However, it should be noted that this metric only captures quantity and is no indication of the quality of training provided. Moreover, private school education in the UAE is very heterogenous and there is a great deal of variation between each school, especially in comparison to public schools.

\section{More Demanding Workloads and Stress}

\section{Key Takeaways:}

- Teachers and administrators are working more and have fewer breaks in which to prepare for remote lessons, coordinate with others, or relax.

- Students' average distance learning school day in the UAE is 8.4 Bhours with few breaks and large differences between schools/curricula.

Administrators and teachers both reported that their work day has become more demanding. While one reason is that working hours have become longer for some, many administrators and teachers say the real stressfactor is that their day has become busier with little to no breaks between lessons or meetings. For instance, one teacher responded that it is an "exhausting experience especially because all classes are in a row from $4 \mathrm{pm}$ to 7:30pm. Breaks should be longer."

While the absence of breaks and adequate time to coordinate with others is one concern for both groups, the "huge amount of work in preparing and designing lessons and activities" is another. While this additional workload will be discussed for teachers below, administrators reported being under particular stress although receiving little support. For instance, one surveyed administrator emphasized that the

\section{Schools without eLearning Preparation before COVID-19 face Greater Challenges}

According to a former Dubai school principal, schools' current distance learning preparedness and training needs for staff and students is largely dependent on how much time and resources they invested into eLearning prior to COVID-19. In his opinion, schools that are only starting their transition now face tremendous challenges because a period of crisis is not a good time to be conducting preliminary training. If students and staff were not already familiar with the learning platforms being used, primarily Google Classrooms or Microsoft Teams according to our survey, the transition to distance learning was and continues to be more difficult and stressful for all participants. Some teachers reported they are mitigating the changes by digitizing old teaching methods and materials, such as taking photos of worksheets, to share with their students. Our interviewee further explained that assessments and grading have been sidelined during the past weeks, which means very little direct feedback is being given to students on their progress. 
"workload put on senior management by the Board

of Governors is ridiculous and unrealistic. Teachers

workloads have been reduced for their well-being but nothing has been done for the senior management."

Statements like these are supported by our survey findings, indicating that administrators spend 7.1 hours per day supporting staff, students, and parents on average. The scope of their hours spent on support, however, varies greatly between 5.9 at public schools to 9.3 at private MoE and IB curriculum schools (figure 3). In addition to this, they spend 3.5 hours, on average, on preparation, with this number reaching 4.3 hours at private MoE schools (figure 5). This means that -as an extreme example- administrators at private MoE curriculum schools report to currently have 13.6 hour work days, likely with

Figure 3: Hours of Staff, Students, and Parent Support per Day (Administrators)

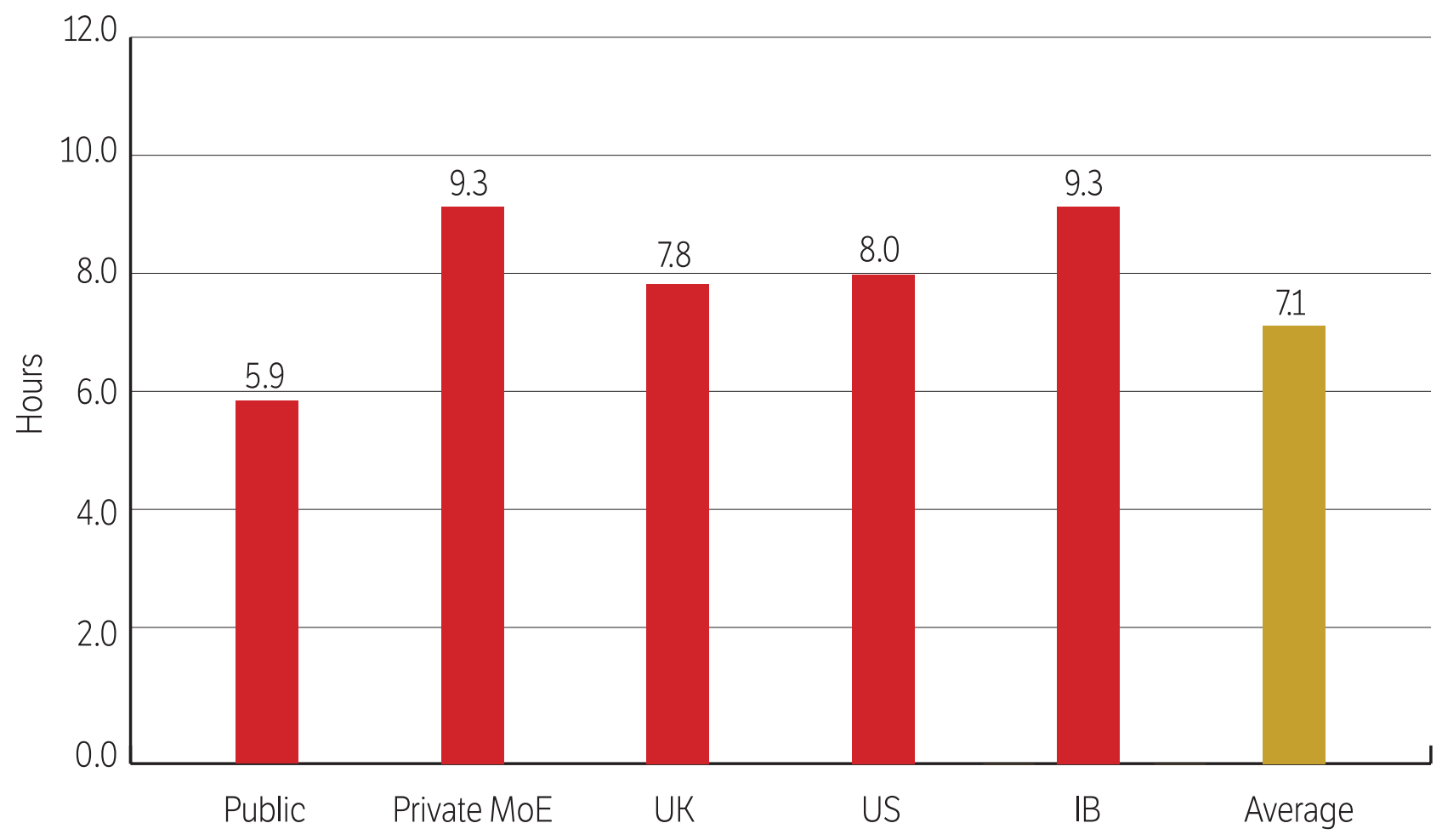

Figure 4: Hours of Online Interaction with Class per Day (Teachers)

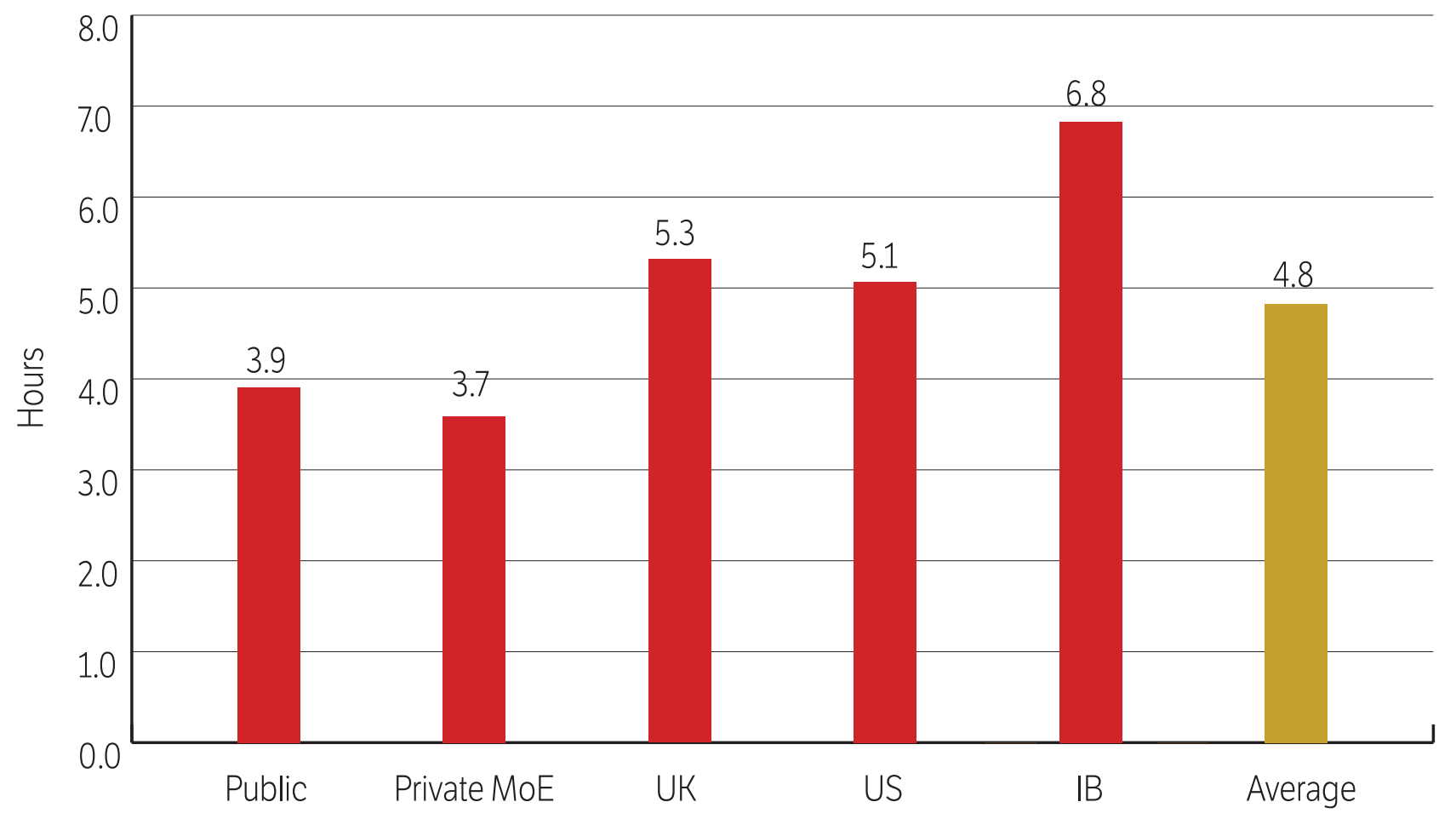


little to no breaks. One administrator added that the emotional and health impact of the current challenges and stress on all groups should not be underestimated:

"School can't be duplicated digitally without having fully planned ahead. This was unforeseen. We should consider the emotional impact of the situation on staff and students and the health impact of 8 hrs screen time on children."

Similar to administrators, the workload of teachers can also be separated into two overall categories that cause stress in different ways. One is the time spent on interacting with their students, and the other is time spent on preparation. As discussed above, while working

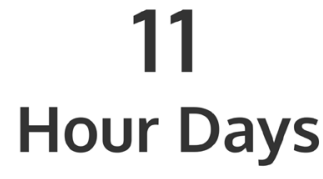

for teachers at private schools with IB Curriculum

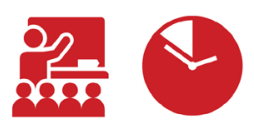
hours increased for some -with teachers at IB curriculum schools reported having 10.8 hour work days- many complained about the absence of breaks during the day, as well as additional tasks that add to their stress levels and make their work more demanding.

On the one hand, teachers reported spending 4.8 hours on average interacting with their classes and students. This interaction ranges from 3.7 hours at private MoE to 6.8 hours at IB curriculum schools (figure 4). More specifically, 32\% of teachers spend more than 6 hours per day interacting with their students (figure 5). One teacher shared that he finds "it hard to give feedback and make lesson plans when I teach 5 hours a day."
Figure 5: Demands on Teachers' Time

\section{Demands on Teachers' Time}
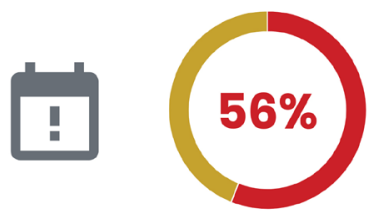

spend $3+$ hours per day on planning
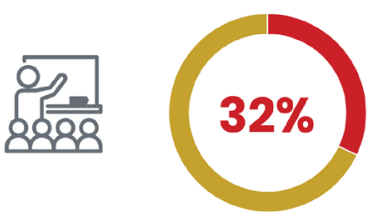

spend 6+ hours per day on teaching

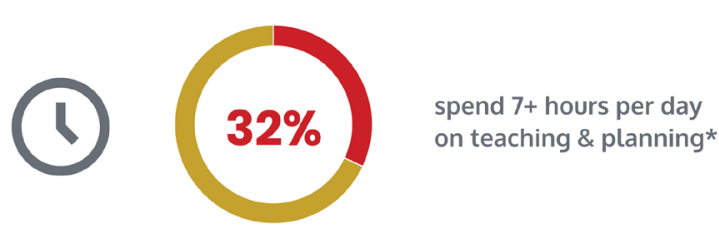

*This excludes time for administrative tasks, breaks, and meetings.

On the other hand, teachers reported spending an additional 3.8 hours, on average, preparing for their classes (figure 6). For teaching and planning related tasks alone, 32\% of teachers reported spending more than 7 hours per day (figure 5). Overall, teachers are spending 8.6 hours, on average, on preparing and teaching, which excludes other administrative tasks, meetings, and breaks. It is the combination of all of these that has led to more demaning work days and additional stress than in-person school days.

Compared to an in-person school day, teachers reported

Figure 6: Hours per Day Spent on Distance Learning Preparation

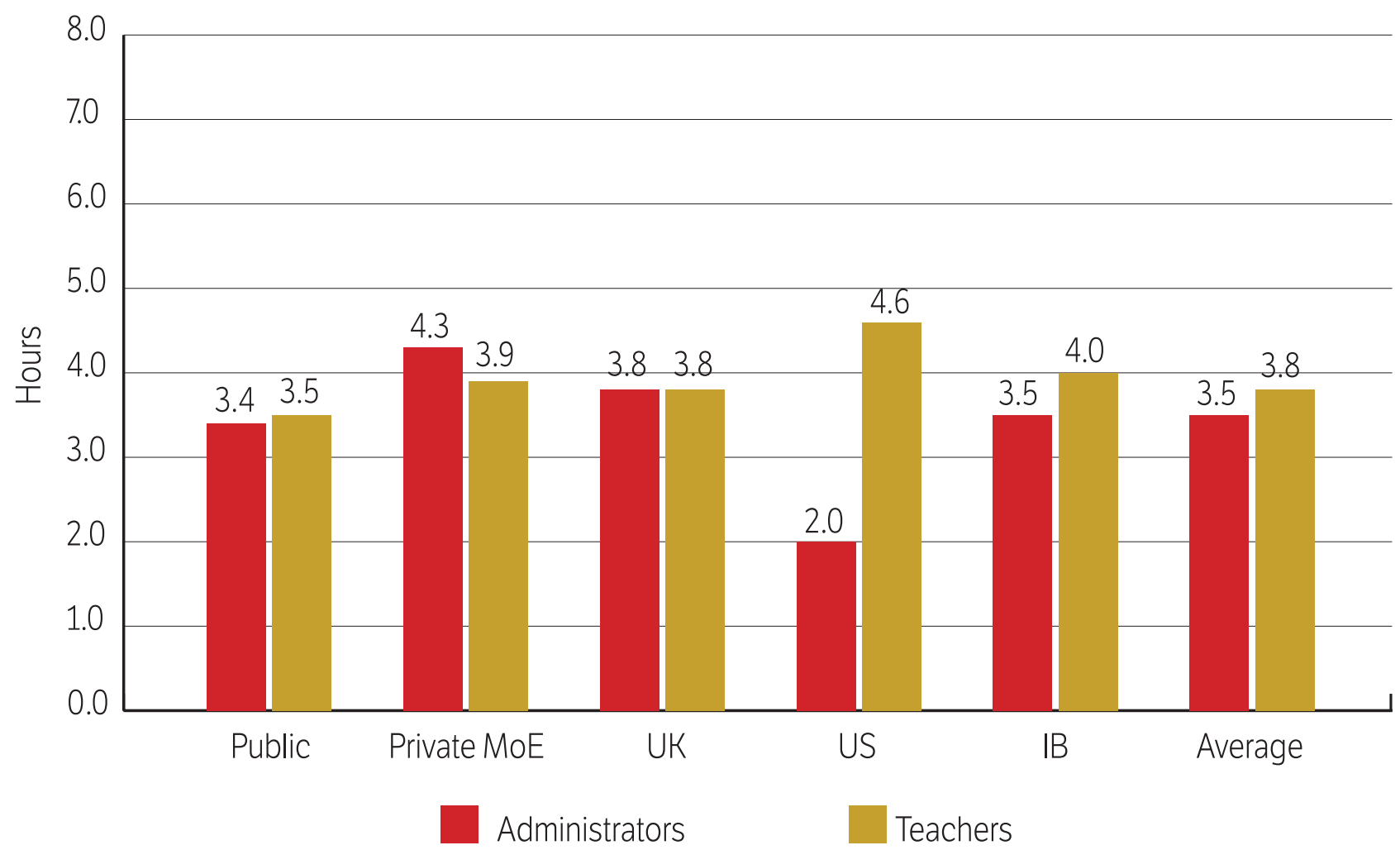


spending more time on instructing and being available for students, as well as preparing materials. They also reported having to digitize all materials and interactions, which require more of their time. An in-person school day reportedly has the advantage of scheduled breaks, set times for student interactions, and the ability to better organize unexpected incidents on an ad-hoc basis. Against this background, teachers described the current distance learning environment as more demanding, stressful, and exhausting than regular teaching. This is supported by statements like the following that also raise other issues teachers have to face, such as threats of salary reductions (see also Rizvi \& Clarke, 2020) or their work being evaluated during these challenging times:

"Constant emails threatening reduction in salary. This isn't helpful. The children should be the priority. Not enough interaction between the children."

"The pressures to produce work and thinking that someone is watching your lessons constantly."

Students reported different factors as particularly stressful in comparison to administrators and teachers. While teachers reported difficulty in interacting with students as a time problem, students experience this as a serious challenge to their learning. For instance, one student emphasized that distance learning has a "very bad impact. With the pressure of $100+$ students in one session, the teacher does not have time to answer all our questions and sometimes does not hear them." One student also described their teachers as being "unprepared, and the work given to us takes extensive time and effort to simply keep us students busy. Quantity is favored over quality. It's a mess."

Figure 7: Hours of Distance Learning Classes per Day (Students)

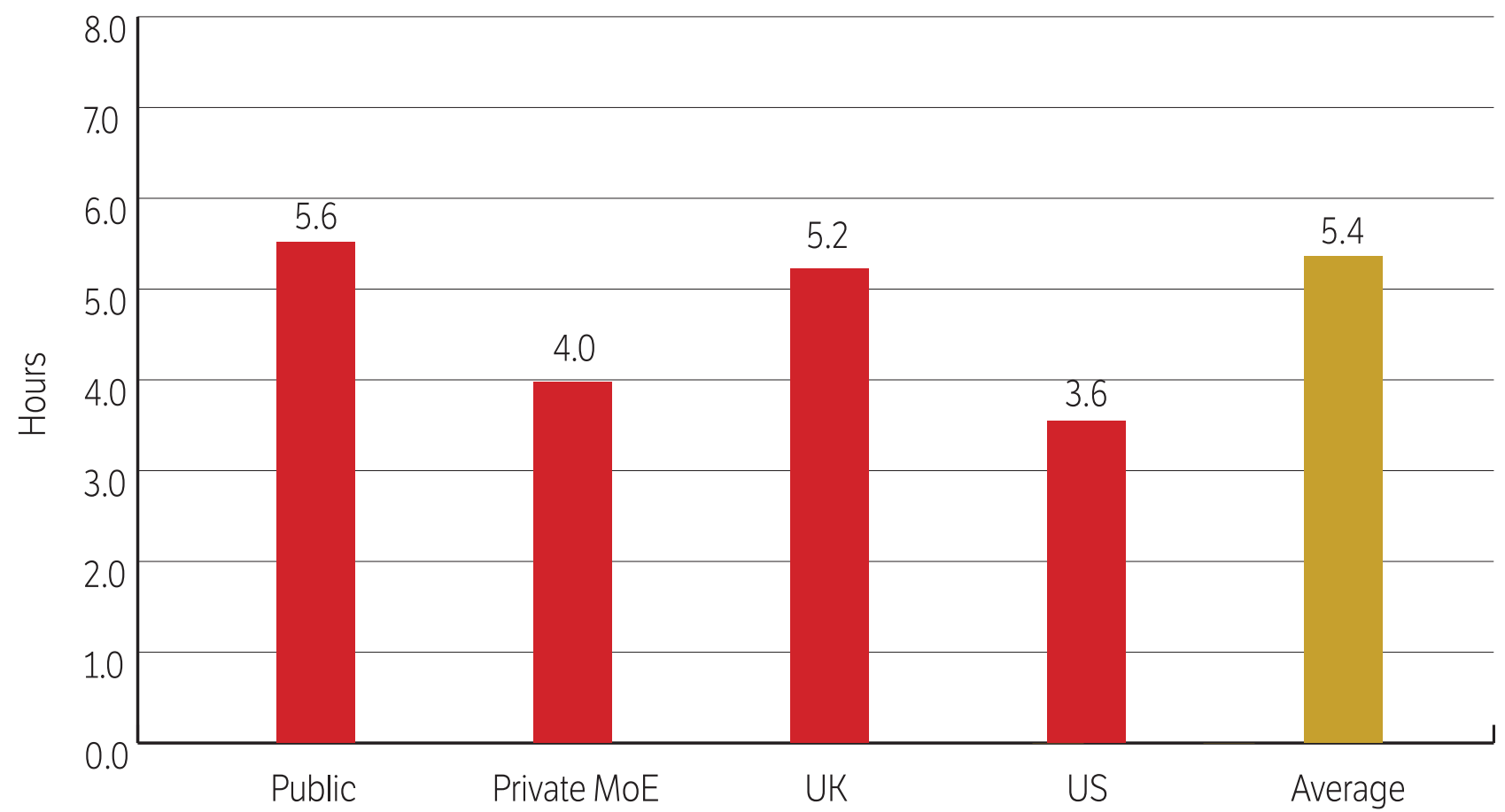

\section{Inspections of Distance Learning During the Crisis: Help or Hindrance?}

The newly introduced inspections, conducted on a regular basis, are another stress and source of uncertainty for teachers also contributing to long working hours (see also Nasir, 2020a). In this context, participants feel that these inspections focus on a rigid checklist rather than encouraging much needed flexibility. According to one interviewee, inspectors log into classrooms unannounced. While teachers understand the importance of unannounced visits, in practice these inspections are generally a disruption to any lesson that is taking place at that time. In one example, our interviewee shared that a teacher was reading a story and stopped to ask their students for their opinions, allowing them to shout out their answers in the meeting room. All of a sudden, a visitor/inspector appeared saying: "Your classroom is out of control. It is too loud!" This resulted in a discussion between the inspector and school staff after the session. The inspector complained about the teacher's classroom management while disregarding and not valuing his planning and reasons for using this method. Understandably, the teacher felt this was not a fair assessment and that their work was not appreicated. 
Figure 8: Hours of Preparation and Homework per Day (Students)

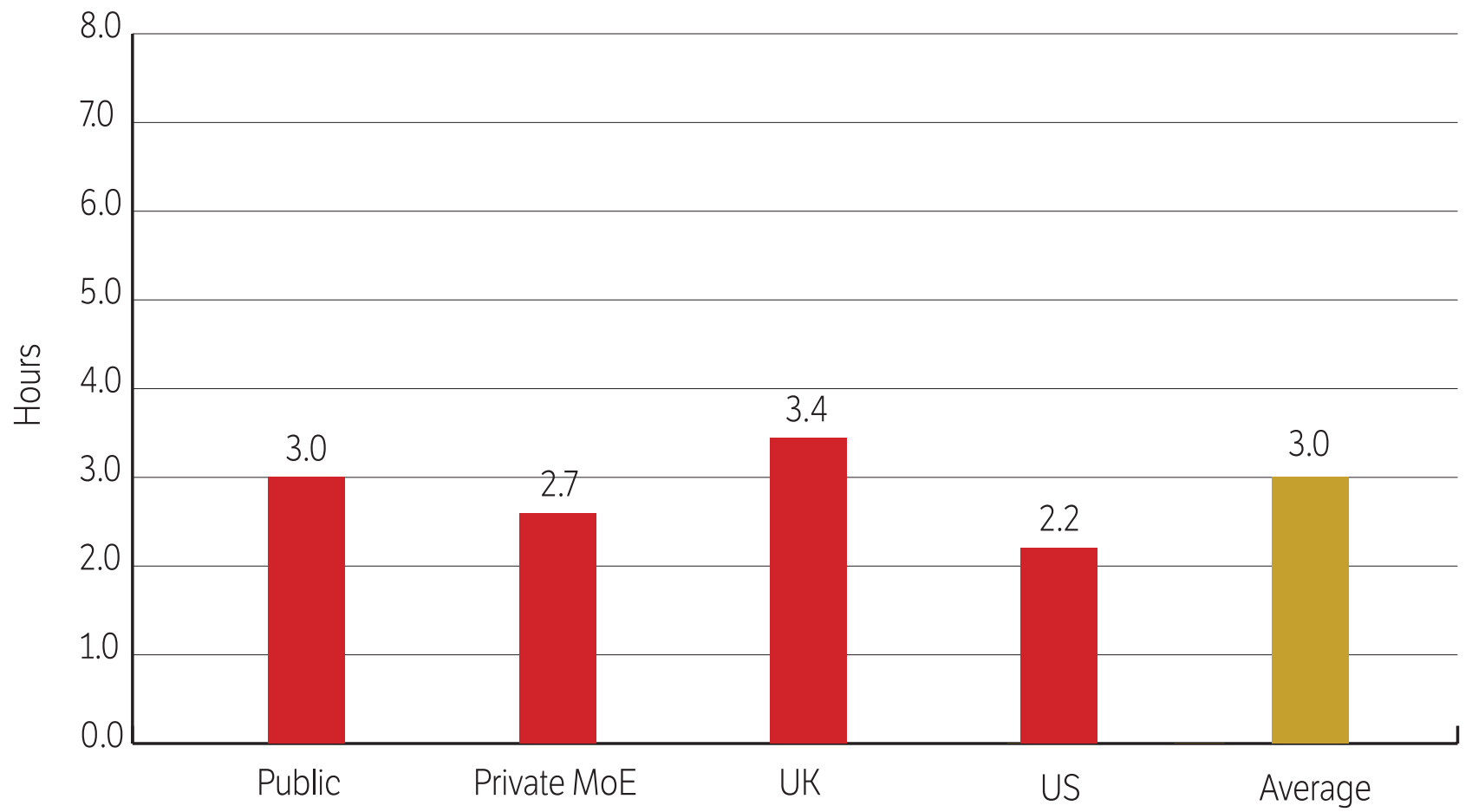

In addition to these lesson-related challenges, a concern that students share with administrators and teachers is the time they spend each day on distance learning, with parents' and students' workload having been raised as an issue in the national news as well (see Zaman, 2020). Our survey data supports those concerns and shows that students at public schools have the longest average school day online with 5.6 hours of classes and an additional 3.0 hours of preparation and homework (figures 7 and 8).

Students, however, reported that their concerns

about time are more complex than just the amount of hours they spend online. It also concerns the overall organization of their distance learning school day. For instance, evening classes are experienced as "very time consuming and tiring". With regards to the distribution of lessons throughout the day, one student emphasized that schools should

"make the time shorter. To be honest it's really difficult to learn. We start from 9:00 and end at 1:25, then from 4:30 till 6:35. In addition to that we have a lot of homework and projects we need to submit. It's very

\section{High Stress Levels, Long Hours, Homework, and Screen Time}

One Dubai school principal shared examples of the challenges faced by schools, teachers, students, and parents, including increased stress levels, long hours as well as too much homework and screen time for students. During the rapid transition to distance teaching and learning, schools have not reduced their expected learning outcomes and still run 40-minute classes. However, teachers are very likely not to cover everything in class and tend to assign the rest of the expected learning outcomes as homework. With this in mind, the principal explained that students have around 5 class periods, which means 5 subjects with homework assignments, as well as additional assignments and speaking tests for Arabic and English, making for an exceptionally high workload. The principal further explained that the ministry advised to only assign homework in 2-3 classes, with priority given to scientific subjects for cycle 3 students at the expense of social studies. At this particular school, the elite streams also have to self-learn for a specific period each day. In response to this, students in grade 11 complained that they are sitting in front of their computer until 11 PM in classes, after which they must continue studying to prepare for tests. This school is attempting to tackle the problem by reducing homework.

The school has learned that parents are also tired and exhausted from sitting in front of their devices for long periods of time. Furthermore, parents, particularly mothers of cycle 1, pre-KG, and KG students, report facing difficulties keeping their children seated for a long time and often have to provide support and discipline throughout the day, sitting with their children for the duration of their lessons. 
stressful and we only get to spend a short time with my family during these rough times. Anyways I support what the UAE has done for its people. I am proud to be an Emirati every day."

While students spend 3.0 hours, on average, on their homework (see figure 8), the amount has reportedly increased with the introduction of distance learning as well. One student explained:

"huge heaps of homework are thrown on us because the teachers are unable to cover what they need to in class. There are also untrue expectations that we have nothing better to do because we are stuck at home which is not true."

Distance learning is particularly demanding for students. There are challenges that are unique to this group, which should be reflected better in future responses to COVID-19.

\section{Working Parents face additional challenges - particularly those with large families or living in cramped accommodation}

\section{Key Takeaways:}

- Many families, especially those that are poorer, have limited space

- Working parents have limited time and resources to support their children and are under a great deal of stress and pressure

- Distance learning can foster economic inequality Household size and the amount of space that people have within their homes is a key factor concerning the success of distance learning. Our research finds that public schools, as well as private schools following the MoE and US curricula, have the largest families, with close to 7 family members per household. For over two months, during the peak of the crisis, parents and children were all working from home together. While some of these families may have large houses and plenty of space to work, many live in cramped accommodation with children sharing rooms. In this context, half of our surveyed parents responded that their children have to share a room as they engage in distance learning. For parents with limited space and time, as well as for their children, remote working in combination with distance learning at the same time has proved to be an immense challenge.

\section{Parents are generally stressed and under high} pressure. While schools, for instance, started threatening parents to suspend distance learning if their fees would not be paid (see Sircar, 2020), surveyed parents described additional challenges in the openended responses:

"Managing time with my family -working longer hours therefore family relationships are suffering. No quality time with my children." (Parent \& School Administrator)

"Some students' parents are still working through this pandemic and we have to adjust deadlines and be understanding of that fact and that they may not complete all their work every day." (Parent \& Teacher)

"Children cannot all be online at the same time especially where there are numerous children in the family and only one device." (Parent \& Teacher)

"I cannot control what my child is doing. He does not

Figure 9: Hours of Distance Learning Support for Children per Day

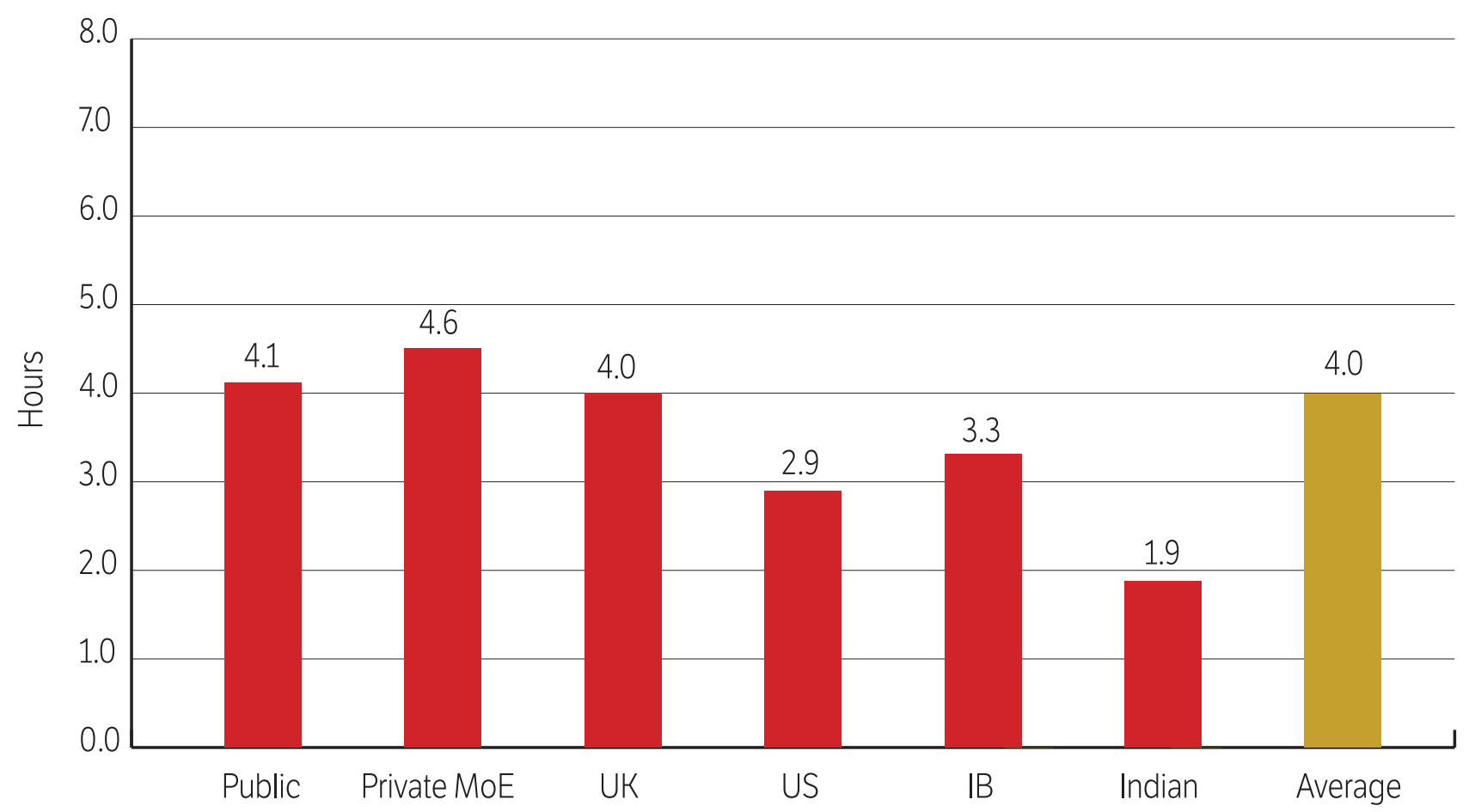


sit in the same room. I have to trust he is engaged. Often, he finishes his work early (sometimes very early) so he then is watching a series in the downtime. That is unacceptable, as for me, school is school time. I struggle to understand how he manages to finish an hour's lesson in 10 minutes and is allowed to come away from the class. And yet his grades are top level. He has come out of 3 Arabic lessons after 10 minutes. I want him to learn the language, how does 10 minutes work?" (Parent)

Our survey responses also show that parental support for childrens' distance learning -measured by hourssignificantly varies between curricula with an average of around 4 hours per day (figure 9). For instance, parents at Indian curriculum schools (1.9 hours), likely due to other obligations, are not providing as much support as parents at private MoE schools ( 4.6 hours), a difference of almost 3 hours per day.

Overall, and because of the different levels of parental support and barriers in access, distance learning has the potential to foster economic inequality by exacberating the exisiting gap between students of different socioeconomic backgrounds. Poorer students are at particular risk for at least two reasons. First, as figure 9 indicates, their parents less likely have the resources to support them with their distance learning school or homework. More affluent, wealthier parents with higher levels of education are typically more involved with their child's learning. Second, schools with some of the lowest fees, such as those offering a private MoE curriculum that poorer students are more likely to attend, had the poorest performance in the most recent PISA test (OECD, 2020). Students at these schools are of particular concern because in addition to possibly receiving a lower quality education, they reportedly are also more likely to come from a larger family. This makes them less likely to have a room of their own for distance learning, or have their own device, affecting their ability to concentrate on and engage in distance learning.

As an example for those students that are particularly vulnerable, a teacher explained that these could be children "who have English as a second language and parents who are unable to support[, and] because of the lack of English [they] are seriously disadvantaged." A larger issue that goes beyond socioeconomic backgrounds is that boys, for example, "have not been doing well in school this century [...] [with their] scientific literacy [...] decreasing faster than that of girls, and their reading levels are one school year behind that of girls." (Mann, 2020) Boys disengagement in education has been a rarely discussed, yet pressing issue in education systems of developed countries long before COVID-19 (Ridge et al., forthcoming), and the current distance learning situation will likely disadvantage this group further. Consequently, one principal believes that teachers need to be prepared for even greater disparity and heterogeneity in their classes than before the pandemic, and vulnerable students need particular support.

\section{Children with Learning Disabilities or Special Needs lack sufficient support}

\section{Key Takeaway:}

- Approximately $60 \%$ of teachers in private schools and $50 \%$ of all principals at public and private schools do not believe that students with specials needs are being adequately supported

Figure 10 indicates that the majority of teachers do not believe that children with learning disabilities are getting the support they need, an administrator added that "special needs students and students with learning disabilities are

Figure 10: Teachers' Beliefs Regarding the Preparedness of Students with Learning Disabilities

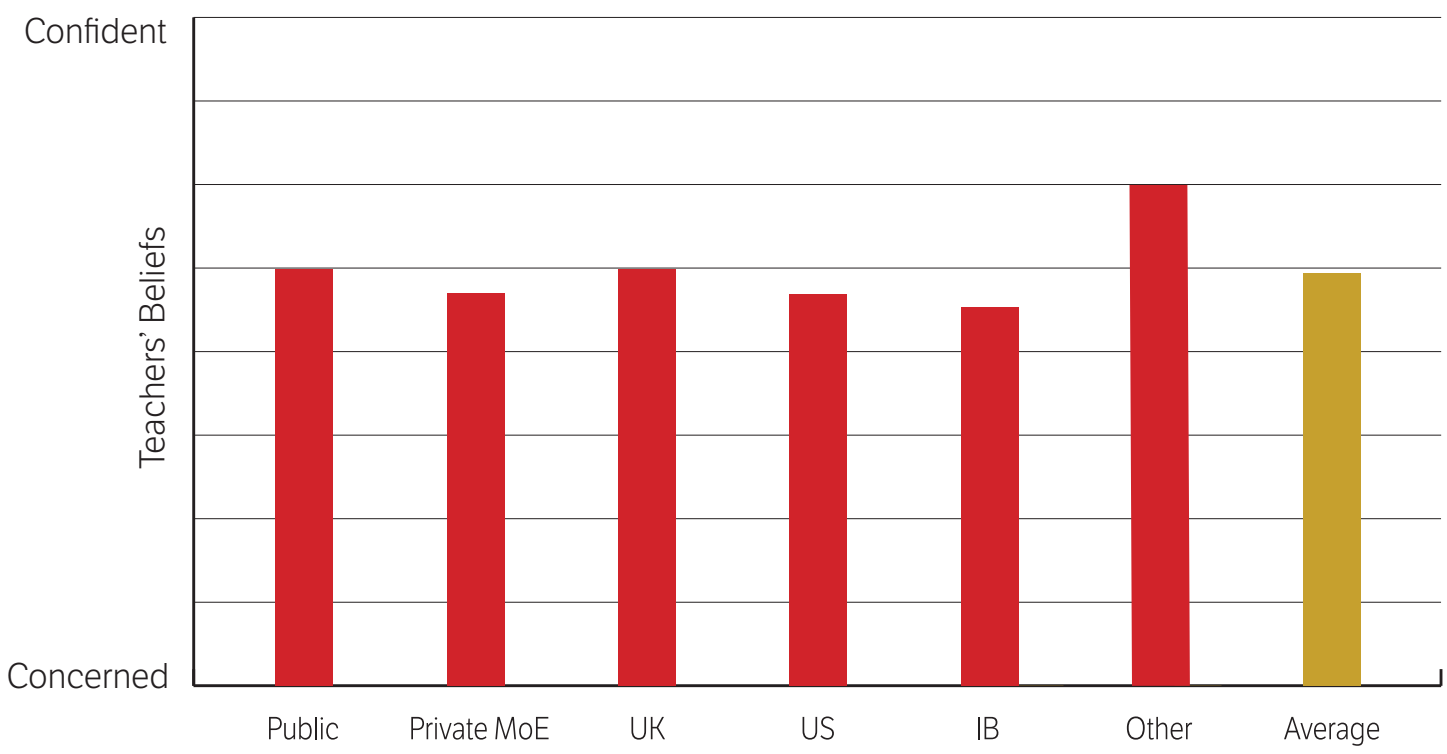


at some potential risks. Mostly all are not prepared for such an emergency situation." This concern is supported by other survey respondents who stressed that:

"The amount of time needed to prepare materials for all my students [is too high]. Although I know how to use all the platforms, I feel I haven't received enough training. My students of determination need additional contact sessions, and this is not taken into consideration. $90 \%$ of most of my classes do not participate and I cannot force them to." (Teacher)

Based on these findings and responses there are many challenges unique to this vulnerable group that remain unaddressed but deserve urgent attention while data remains scarce.

\section{Key Challenges}

\section{Scarcity of distance learning resources and little to no training for administrators, teachers, students, and parents:}

- Training needs are unaddressed or undefined

- Involvement of parents in their children's distance learning is concerningly low in some groups

- Crisis management plans are/were nonexistent, which led to a disruptive transition to distance learning

\section{Workload and demands of individuals during this unprecedented time are unreasonably high:}

- Screen time is too high

- Teachers have little to no time and space to coordinate with colleagues and provide feedback to students

- Administrators face unreasonable expectations and need to manage through the crisis with little help

- Working parents face difficulties balancing their own work with supporting their children's education

\section{Educational and emotional needs of the most vulnerable students are unaddressed:}

- Vulnerable students, especially those with special needs, lack the necessary learning and psychological support

- Vulnerable students are also less likely to have access to the technology required for distance learning or have a dedicated space for learning, causing them to be most affected

\section{Recommendations}

\section{Schools Need to Prepare for Future}

As schools look ahead to phase in onsite teaching in the near future, until there is a COVID-19 vaccine, we face the risk of another global wave of the virus or local outbreaks in schools and communities. Each school should put the necessary measures in place, including having 'emergency learning kits' ready for every student in case that risk becomes a reality. This includes using various mediums of instruction tailored to the diverse needs of students, particularly those with special needs and those from low socioeconomic backgrounds. Other countries in the GCC have started educational TV channels and radio stations to provide alternatives to an online-only delivery of education. Another possible approach that can serve as a model is the Alice Springs School of the Air in Australia that has successfully implemented remote teaching for decades. This example emphasizes that distance learning has existed as a niche for some time, and there are great things to learn from these schools. For the School of the Air, screen time tends to be significantly reduced and many tasks are done offline with teachers often mailing physical materials. Other countries, such as Portugal, have started partnerships with national post services to deliver educational materials to students' homes.

Distance learning and teaching tools that are being used now could become part of regular teaching once students and teachers return to school. When technological solutions are implemented in regular teaching activities, future transitions will be smoother; however, this would need to include continued investment in resources and training. In addition, a reduction in teaching hours should be considered, which would also give students more time to learn on their own and teachers would have time to share best practices in the context of distance learning.

Financial liquidity needs to be a priority of school operators. The limited financial liquidity of some schools has emerged as a pressing issue as schools 
face unforeseen financial difficulty due to COVID-19. This signals that emergency funds should be set aside to ensure a school's financial liquidity for several months as a buffer during crises periods. This will ensure that schools can maintain operations, including continuing to pay salaries for all staff, especially those with low salaries who are most affected by salary cuts or job loss.

\section{The structure and content of the school day needs to become more flexible}

The current transition from onsite to online teaching and learning seems like the early days of the transition from broadcast television to online streaming over the last decade. Online streaming does not necessarily offer higher quality or greater choice, but its value is in its convenience and availability on-demand. People can choose when to watch what they want to watch, instead of the schedule being dictated by network executives. We need a realization of this crucial difference in our schools as well. Our data shows that screen time is tremendously high, and the structure of the school day is very rigid, preventing students from learning at their own pace when this would be possible in higher grades. Currently, the school day is effectively being livestreamed into students' homes despite the fact that there is little to no need for this. Instead, we propose that more flexibility in scheduling and modes of learning should be introduced to enable students to choose when and how they want to learn. This requires trust from teachers and administrators, as well as students to be responsible, self-motivated, and capable of engaging in self-directed learning. This will require training for both teachers and students, as well as a thoughtful and careful transition to completely new mindsets and frameworks of learning and teaching, which bring with them didactical and methodical challenges.

One possibility that will enable more flexibility and choice for students to learn could be a greater reliance on project-based learning. Project-based learning provides an opportunity to learn several subjects at once while working on a dedicated problem (cf. Lenz et al., 2015). For instance, by learning about coral reefs in the UAE, students can learn about biology, chemistry, and mathematics, as well as English and history. As a result, it would only be necessary to touch base with the whole class a few times each week, giving teachers the time for individual conversations with their students. Also, students could then -as emphasized above- learn ondemand, pulling the resources they need from the online platform they are using and approaching learning at their own pace, while the teacher provides accountability to ensure that progress is happening. Nonetheless, one big challenge of project-based learning is that all stakeholders -students, parents, teachers, and administrators-will need to learn how to responsibly and productively use the heightened flexibility.

\section{3 Policy makers must prioritize support for the most vulnerable groups}

Specific groups are at greater risk, such as special needs students and those from low socioeconomic backgrounds, and require additional, specialized support. In addition, there should also be a focus on phasing the youngest students back into school

first. Thisisimportantbecausethey generallyaretheones with the least developed ability for self-directed learning. All these groups will need additional support over the coming weeks and months - especially if there should be other local or regional outbreaks. One possibility to mitigate this risk and these groups' exposure might be to develop plans for more decentralized ways of teaching within disadvantaged communities or neighborhoods. For instance, a teacher from a nonrisk group could come to a designated building in a neighborhood each day and be available if students need help while they are engaging in distance learning. Students who are most at risk of being left behind due to their poor learning environments at home or the absence of parental support, as well as other factors, could then be better supported at no or very little additional cost.

\section{4 Greater parental involvement in education should be encouraged}

The role of parents has changed dramatically in response to COVID-19 and distance learning. While our past research has stressed the importance of parents being involved in their children's education for many years, our findings have now become even more relevant (cf. Ridge, \& Jeon, forthcoming). Parents need to be actively involved -in particular academically- in their children's learning and provide opportunities and time to talk about questions they might have about certain materials, but also about the current situation as a whole. We know that parental involvement is dependent on the parents' own education, and also on the time they have available for their children, which makes it necessary to support parents during these times as well. One option could be for schools to create support groups for parents, and that schools or teachers reach out to them for having regular follow-up conversations. In addition, schools could provide materials with best practices so parents get an idea of what they can do to support their child best during the coming weeks and months. 


\section{Key Recommendations}

\section{Schools have to prepare for future outbreaks}

- Emergency learning kits

- Partnerships with national postal systems to deliver printed learning materials

- Continued investment in resources and training for e-learning

- Have an emergency fund or financial buffer to maintain liquidity during crises periods

\section{More flexible content and structure needed in schools}

- Use various mediums of instruction both online and offline to meet the diverse needs of students

- Use more diverse assessment methods, including project-based learning

- Reduce instruction hours to reduce burden on students and reduce screen time, while giving teachers more time to engage and share experiences and practices with colleagues

\section{Prioritize support for the most vulnerable groups}

- Focus on bringing younger students back to school first

- Implement decentralized schooling for high-risk groups to provide space for learning that may not be available at home

\section{Encourage greater parental involvement in education}

- Create parent support groups

- Provide more training on how to use online learning platforms

- Create closer teacher-parent links to provide support for at-risk families

\section{Concluding Thoughts}

Our research reveals that the impact of the COVID-19 crisis on education in the UAE has been extensive. On the plus side, schools and families have acquired new and valuable technology skills, and the importance of teachers has been reaffirmed. However, in the absence of free public education for all students in the region, we also see a growing divide between socioeconomic groups. One effect is that those expatriates at the lowest end of the socioeconomic scale are most at risk of being unable to access education due to a lack of resources and access to technology. In addition, parents who

\section{Acknowledgements}

The authors would like to acknowledge the contributions made by David Dingus in particular, as well as those made by Max Eckert and Sarah Han. might already have little money left because they lost their job are also under stress to find the money to pay school fees to ensure that their children's education is not stopped completely. In the UAE, we need to see greater government intervention and support to protect those families who are most at risk of being forced to discontinue their child's education. Without legal protections and social support, there is the risk that only the wealthy and middle class have access to education while those most vulnerable to job loss and income insecurity are unable to educate their children, creating a poverty trap. 


\section{Back to School: Quick Wins and Best Practices from other Countries}

\section{(partly informed by Oliver Wyman Report, April 2020)}

- Prioritizing students from low-income families that are most impacted by the current situation, as well as young students who have the least developed skills and abilities for self-directed learning, which may also help working parents in particular

- Providing high-tech, low-tech, and no-tech options to build structures for distance learning that can reach all children. Additionally, growing the portfolio of distance learning options also helps to mitigate risks and make learning on-demand:

o Countries, such as Bahrain, South Korea, and Qatar, have created country-wide platforms for supporting the delivery and management of online classrooms

- Bahrain, Saudi Arabia, and Qatar are using YouTube channels to provide students with educational content

- China, Saudi Arabia, and Qatar have also launched educational TV channels

- In Africa and other Southern contexts in particular, learning from their experience during the Ebola outbreak (2014-2016), governments have created or re-activated educational radio programming to reach students even in the most rural areas and those who do not have an internet connection or their own device

- Portugal's government and others have partnered with their national post office for worksheet deliveries to students

- Different forms of subsidizing to support the most vulnerable families and school communities:

- Reducing or waiving rent as well as power and water charges for schools

o Implementing school-fee discounts for parents with salary reductions or job losses

- In Saudi Arabia, telecommunication companies have introduced free data tariffs for the use of approved education platforms

- Providing more transparency over current developments in the sector as well as support opportunities for school operators, administrators, and teachers

- Using all existing spaces in schools to spread students out/keeping appropriate distance

- Building trust inside the system and empowering decision making at the local level 


\section{References}

Juma Al-Majid Center for Culture and Heritage (2020). Juma Al-Majid. Juma Al-Majid Center for Culture and Heritage. https://www.almajidcenter.org/page.php?pid=juma-al-majid

Lenz, B., Wells, J., \& Kingston, S. (2015). Transforming Schools. Using Project-Based Learning, Performance Assessment, and Common Core Standards. San Francisco: Jossey-Bass.

McKinsey \& Company (2020). School-System Priorities in the Age of Coronavirus. https://www.mckinsey.com/ industries/public-sector/our-insights/school-system-priorities-in-the-age-of-coronavirus\#

Mann, J. (2020, June 10). Boys' education: How to get boys to engage, at school and at home. The Sydney Morning Herald. https://www.smh.com.au/national/nsw/boys-education-how-to-get-boys-toengage-at-school-and-at-home-20200601-p54yf2.html

Nasir, S. (2020a, May 4). Six outcomes parents and schools want from e-learning inspections. The National. The National. https://www.thenational.ae/uae/education/six-outcomes-parents-and-schools-wantfrom-e-learning-inspections-1.1014560

Nasir, S. (2020b, May 18). Dubai organisation gives free laptops to low-income families to help online learning. The National. https://www.thenational.ae/uae/education/dubai-organisation-gives-free-laptops-tolow-income-families-to-help-online-learning-1.1021006

OECD. (2020). PISA: Programme for International Student Assessment [Database]. OECD Education Statistics. https://doi.org/10.1787/data-00365-en

Oliver Wyman (April 2020). Education Continuity During COVID-19. Responses Observed and Recommendations.

Ridge, N., Erfurth, M., \& Dingus, D. (forthcoming). Leaving No Boy Behind: Achieving Gender Equality in Education and Beyond, a Case Study of the United Arab Emirates. UNESCO.

Ridge, N., \& Jeon, S. (forthcoming). Father Involvement and Education in the Middle East: Geography, Gender, and Generations. Comparative Education Review.

Rizvi, A., \& Clarke, K. (2020, April 29). Coronavirus: Teachers tell of pay cuts and unpaid leave as summer nears. The National. https://www.thenational.ae/uae/education/coronavirus-teachers-tell-of-pay-cuts-andunpaid-leave-as-summer-nears-1.1012524

Sircar, N. (2020, April 1). Covid-19: Dubai schools can suspend distance learning of students if parents don't pay fees. Khaleej Times. https://www.khaleejtimes.com/coronavirus-pandemic/covid-19-dubaischools-can-suspend-distance-learning-of-students-if-parents-dont-pay-fees

Sutton Trust (April 2020). COVID-19 and Social Mobility Impact Brief \#1: School Shutdown. https://www. suttontrust.com/wp-content/uploads/2020/04/COVID-19-Impact-Brief-School-Shutdown.pdf

Zaman, S. (2020, May 3). Coronavirus UAE: Remote learning workload becoming a stressor. Gulf News. https://gulfnews.com/amp/uae/education/coronavirus-uae-remote-learning-workload-becoming-astressor-1.71259381 


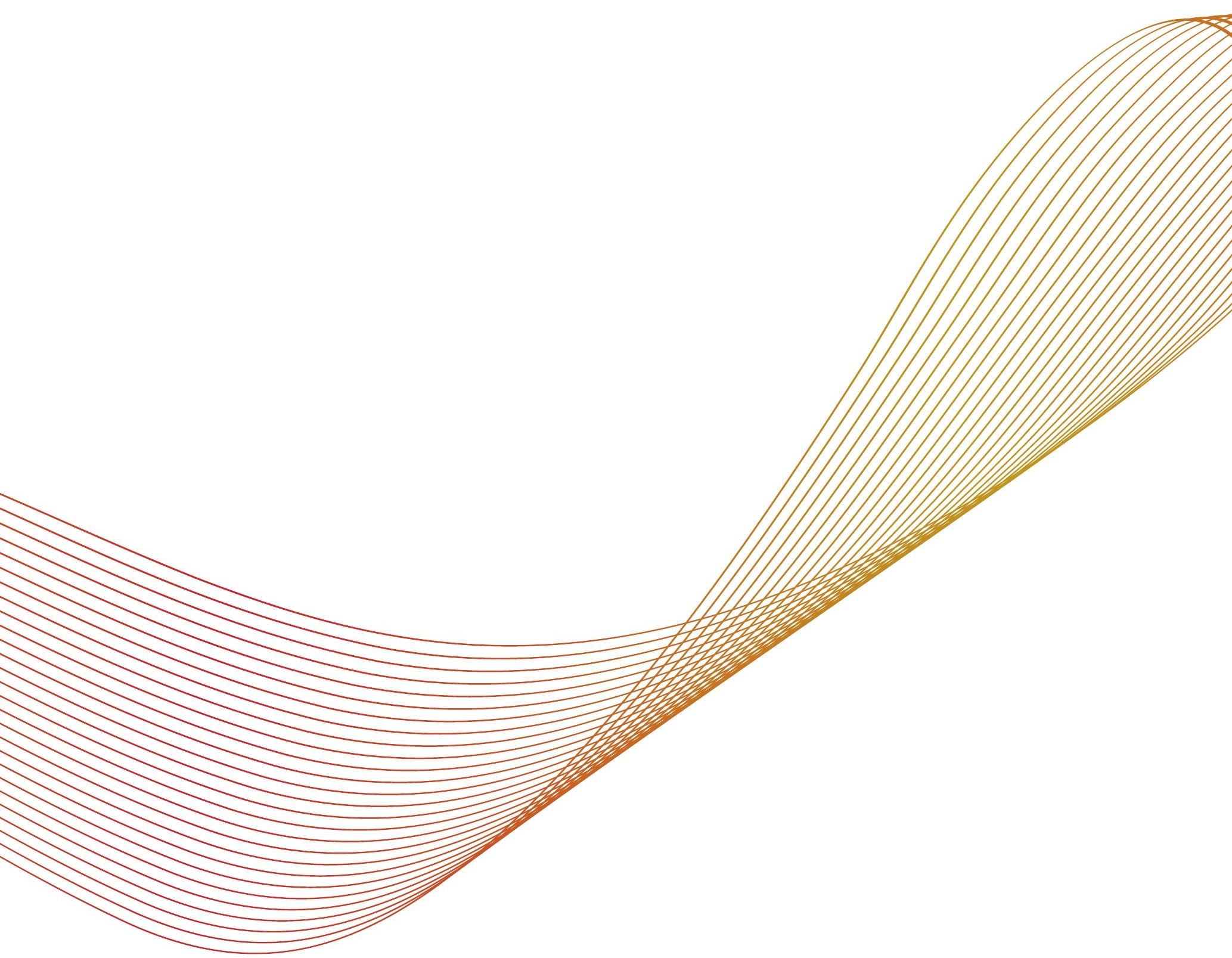

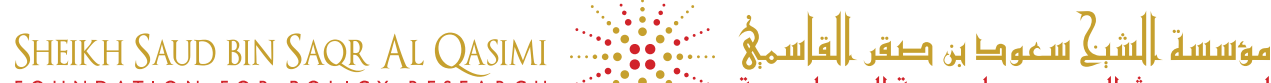
FOUNDATION FOR POLICY RESEARCH

P.O. Box 12050, Ras Al Khaimah, United Arab Emirates • Tel: +97172338060 • Fax: +97172338070• E-mail: info@alqasimifoundation.rak.ae 